\title{
Processing Equipment on the Basis of Operative Parts in the Form of Screw Rotors With Profiled Perimeter
}

\author{
Valery Lebedev ${ }^{1}$, Georgy Serga ${ }^{2}$, Lidianna Chunakhova $^{1}$ and Mikhail Selemenev ${ }^{3}$ \\ ${ }^{1}$ V A Lebedev, Don State Technical University, department «Engineering technology», 344000, \\ Rostov-on-Don, 1 Gagarina ave., Russian Federation \\ ${ }^{2}$ G.V. Serga, Kuban State Agrarian University named after I.T. Trubilin, 350044, Krasnodar, 13, \\ Kalinin st,. Russian Federation \\ ${ }^{3}$ M. Selemenev, Oryol State University named after I. S. Turgenev, 302026, Orel, 95, \\ Komsomolskaya st., Russian Federation
}

\begin{abstract}
The main working body of technological equipment of screw rotor technological systems are screw rotors which present spatial objects with an original geometrical shape of working body perimeter in which component parts and granules of the processing environment carry out simultaneously continuous rotation around the axis of working body and progressive motion, constantly moving along a horizontal axis of working body rotation. This article gives a classification of perimeter forms of working bodies, such as screw rotors, which let to expand technological possibilities of technological equipment and to provide the increase of effectiveness of the production process by means of increase of its amplitude-frequency characteristics. The peculiarity of working bodies in the form of screw rotors is the fact that internal cavity of a rotor has a wavy shape, formed by the sides of a semicircular form. The paper covers on a construction and the principle of operation of machine-tools on the basis of working bodies in the form of screw rotors with a shaped surface on perimeter. The suggested design solutions of processing equipment allow creating highly effective machine-tools for the finishing and strengthening processing.
\end{abstract}

\section{Introduction}

Search of ways to increase the effectiveness of the finishing and cleanup and strengthening operations[1-4] have caused the development and implementation of rotary-screw technological systems into the manufacturing process. According to academician L.N. Koschkin $[5,6]$ they belong to the technical systems of the $4^{\text {th }}$ class which allow to carry out processing by space.

The screw rotors, the main working body of this type of processing equipment, are spatial objects with original geometrical form of perimeter of operative part in which details and granules of the processing environment simultaneously carry out continuous rotary 
motion around the axis of an operative part and a translational movement, continuously migrating along horizontal fulcrum pin of an operative part.

\section{Screw rotors with shaped perimeter}

Constructive options of cylindrical and conical screw rotors, depending on perimeter's geometrical form are represented in Fig. 1.

Change of perimeter shape of external and internal rotor surfaces allows to expand technological capacities of processing equipment and to provide increase in efficiency of processing due to increase of its amplitude-frequency characteristics [7-12].

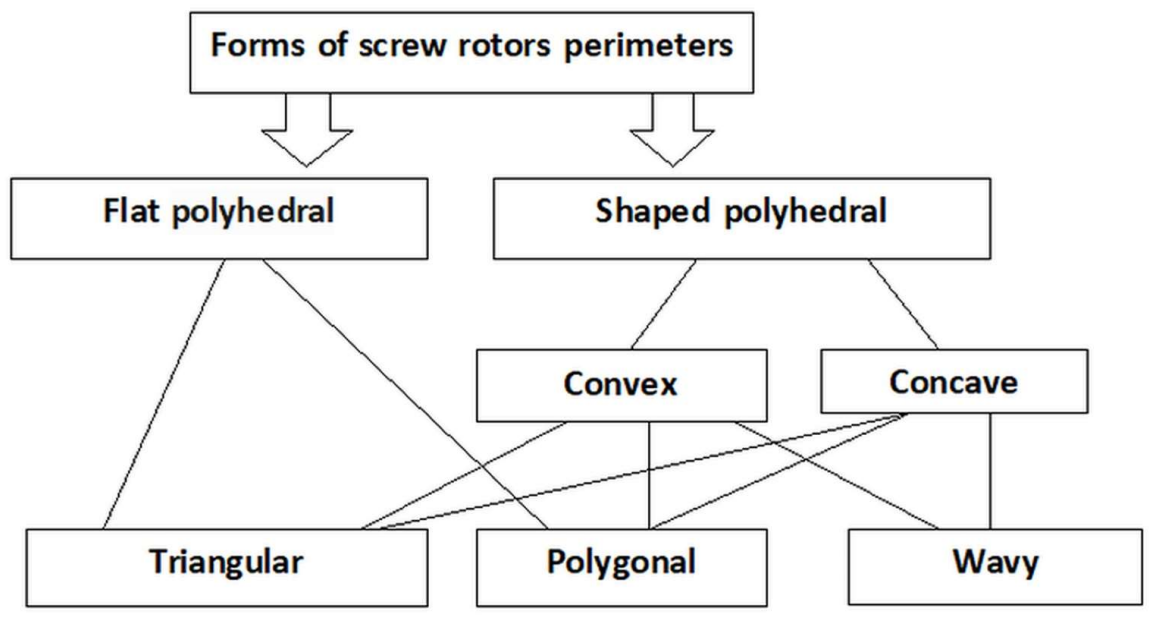

Fig. 1 - Classification of perimeter shapes of operative bodies in the form of screw rotors

As to the peculiarities of operative bodies in the form of screw rotors with shaped perimeter, their internal cavity represents a wavy form created from the sides of semicircular form. Fig. 2, 3, 4 illustrate the types of these kinds of rotors, executed by means of the program complex "Compass-3D".

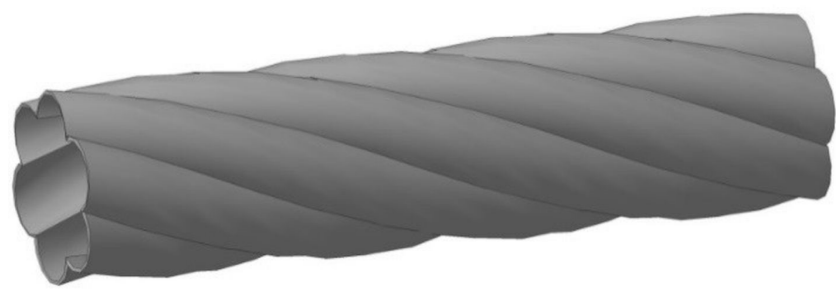

Fig. 2 - Cylindrical screw rotor with convex wavy perimeter 


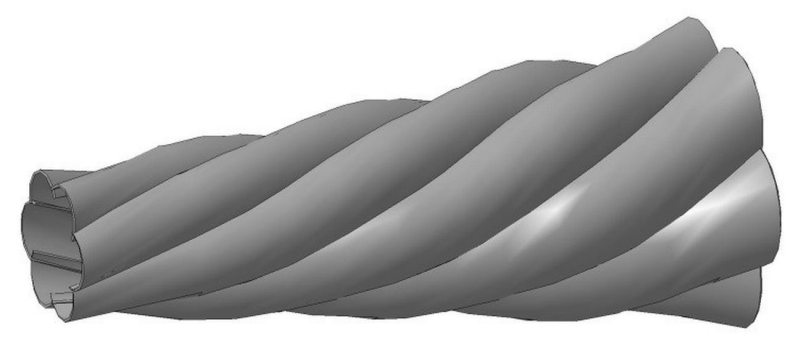

Fig 3 - Conical screw rotor with convex wavy perimeter

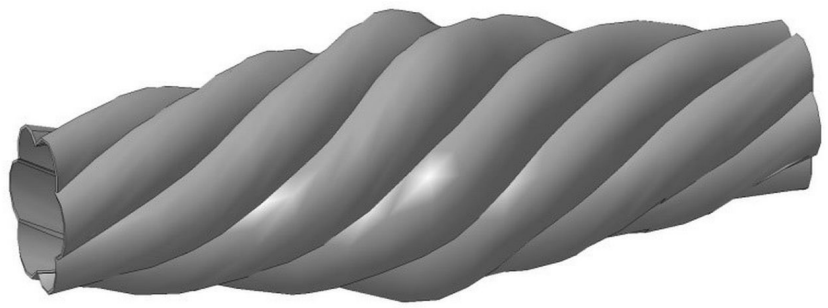

Fig. 4 - Cylindrical screw rotor of a variable cross section with convex wavy perimeter

\section{Design and the Principle of Operation of Processing Equipment With Operative Body in the Form of Screw Rotor with Shaped Perimeter}

The machine for the finishing and cleanup and strengthening processing (Fig. 5) consists of conical screw rotor with convex wavy perimeter 1 , means for loading 4 and unloading 5. Drive gear is not represented in Fig. 3. The screw rotor 1 is equipped with loading and unloading wrist pins 2 and 3 with the help of which it rotates in bearing parts 6 and 7 .

The screw rotor 1 is supplied with loading and unloading wrist pins 2 and 3 by means of which it rotates in bearing parts 6 and 7. Loading nose 8 of loading means 4 enter the hole of a wrist pin 2. Loading means 4 , bearing assemblies 6 and 7 with a screw rotor 1 are fixed on the platform 9. Platform 9 is constructed on four pneumocylinders 10, fixed on a supporting structure 11 . 

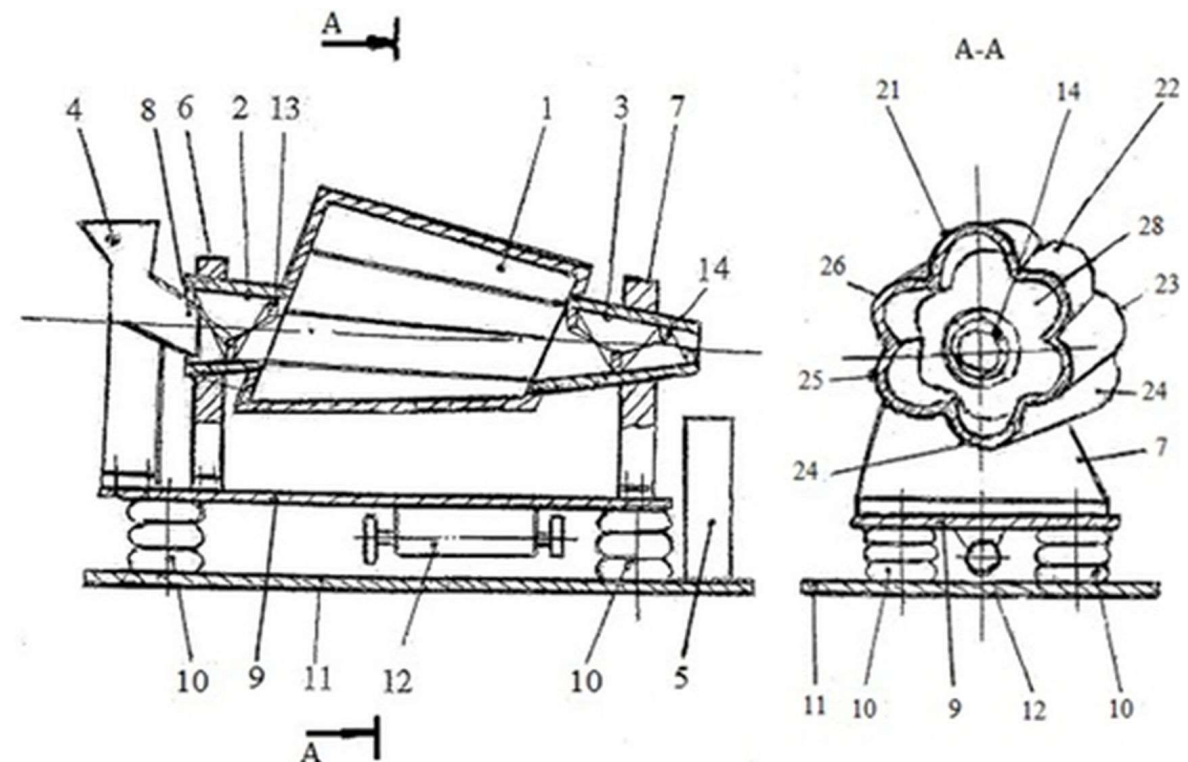

Fig. 5. The machine-tool for the finishing and cleanup and strengthening processing.

To change the speed of longitudinal mass displacement of the processed parts and particles of working environments from loading to unloading in the machine-tool construction for the finishing and cleanup and strengthening processing there is a device (it is not shown on the drawing) for giving a horizon-seeking inclination to the rotational axis of screw rotor 1 . From below a vibrator 12 is attached to the platform 9.

In loading 2 and unloading 3 wrist pins of conical shape, turns of rectangular cut 13 and 14 which provide stable displacement of loading masses in them, are rigidly fixed on their internal diameters.

Screw rotor 1 (Fig. 6) has a wavy shape both on the external and the internal perimeter, which consists of sides of semicircular form 21,22,23,24,25, 26 and corresponds to the shapes and sizes of pockets $15,16,17,18,19,20$. 

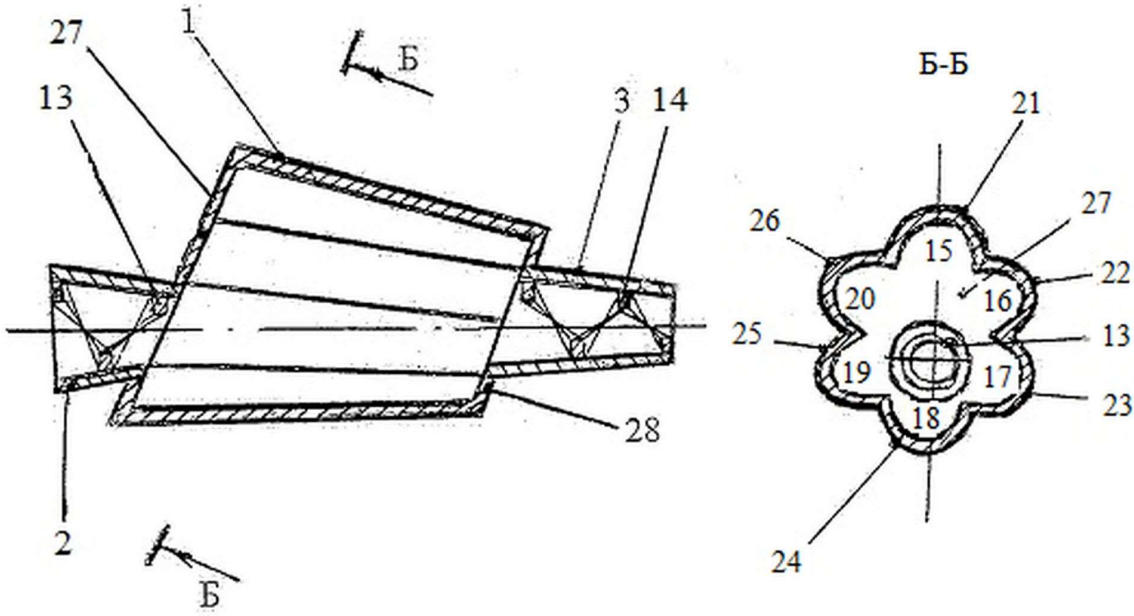

Fig. 6 - The view of conical screw rotor.

The screw rotor 1 is limited by flat end walls 27 and 28 which have the elliptic shape and are situated parallel to each other with a tip at an angle $\alpha$ to its horizontal axis of rotation and are turned relative to each other at a corner $\beta$ (Fig. 7). On their perimeter end walls have a wavy shape consisting of sides of semicircular shapes $21,22,23,24,25,26$.

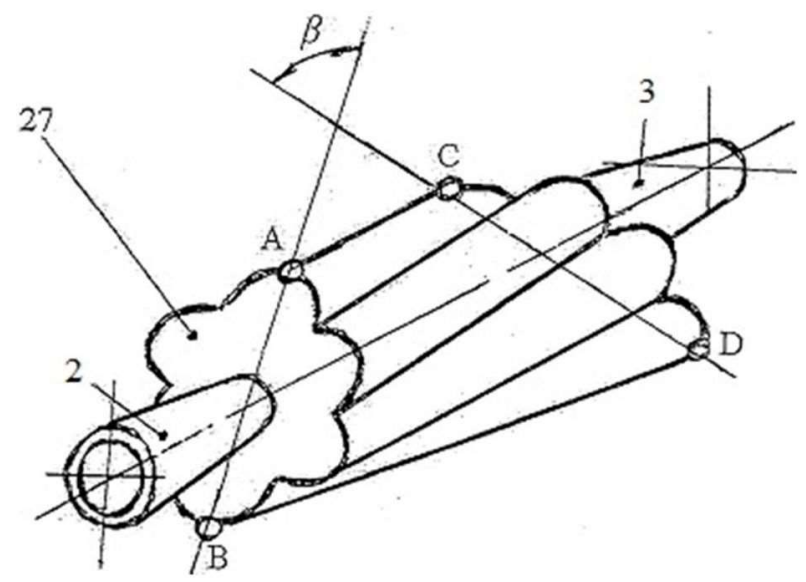

Fig. 7. The view of conical screw rotor illustrating the turn of end walls of the rotor.

The machine-tool for the finishing and cleanup and strengthening processing works as follows. In the screw rotor brought to rotation 1, the processed parts together with a working environment with the help of loading means 4 , first come to a loading wrist pin 2 and then under the influence of turns of rectangular cut 13 displace to the internal cavity of a rotor 1 .

Mass on arrival to the rotor of loading begins to move along elliptic trajectories which sizes change on length in each cross cut of a screw rotor 1 , meanwhile the centers of symmetry of its internal surface, in each element of cross cut, are displaced concerning a rotation axis. And it affects not only the speed and the direction of the movement of loading masses, but also contributes to a creation of 
eccentricity and as a result initiation of low-frequency fluctuations with a big amplitude of a screw rotor 1 .

At switching on the vibrator 12, additional low-frequency fluctuations with a small amplitude appear, which together with low-frequency fluctuations with a big amplitude caused by violations of speed and the direction of the movement of loading masses in a rotor with a convex wavy perimeter promote an intensification of parts processing.

As the rotor 1 is sloping, loading masses make a complex spatial movement in the vertical plane - on elliptic trajectories, and in the horizontal plane reciprocating motion with imposing on these movements low-frequency fluctuations caused by the asymmetric position of a screw rotor 1 and simultaneous impact of fluctuations on them in three mutually perpendicular directions and also by its wavy shape of perimeter.

Therefore the sizes and arrangements of active interaction of streams of loading masses moving particles, not only change during one turn of a rotor, but also their movement becomes more active, low-mobility zones disappear, the power consumption of processed parts and particles encounters of working environments among themselves and with walls on rotor perimeter increases.

Besides the arrangement of end walls 27 and 28 contributes to this process, big axes of ellipses, $\mathrm{AB}$ and CD's of which are turned relative to each other on a corner $\beta$, that changes the direction of loading masses movements and creates zones of various pressure of loading masses on end walls 27 and 28.

Semicircular sides $15,16,17,18,19,20$ complicate the trajectories of loading masses movements, which seize portions of loading masses at rotation of a rotor 1 , lift them above a corner of a natural slope and throw them towards to the rotating sides.

Speed of loading masses movement from loading to unloading can be regulated by change of an inclination angle of the whole machine-tool for the finishing and cleanup and strengthening processing.

The processed parts and particles of working environments, with the help of a conic unloading wrist pin 3 and turns of rectangular cut 14 rigidly fixed on its internal diameter, are removed to the unloading means 5.

\section{Conclusion}

The above suggested designer solutions of processing equipment allow to create highly effective machine-tools for the finishing and strengthening processing, containing elastofixed on the statin with means for loading and unloading working body in the form of a screw rotor with end walls of an elliptic form inclined relative to horizon and with the perimeter created from the sides of a flat and shaped form [13-15].

\section{References}

1. A.P. Babichev Basics of vibromechanical treatment (DSTU, Rostov-on-Don, 1999)

2. A.P.Babichev, P.D. Motrenko The use of vibration technologies for improvement of quality of a surface and operational properties of parts: monograph (DSTU, Rostovon-Don, 2006)

3. A.G. Suslov Technological support and increase in operational properties of parts and their connections (Mashinostroeniye, Moscow 2006)

4. M. A. Tamarkin Rus. Eng.Res. 29, 518, (2009)

5. G.V. Serga Bul. RGATU, 2, 126(2017)

6. V.A. Lebedev, G.V. Serga, A.V. Khandozhko IOP Conf. Ser.: Mat. Sc. and Eng., 327 (2018) 
7. V.A. Lebedev, G.V. Serga, I.V. Davydova, T.V. MATEC Web Conf., 226, (2018)

8. V.A. Lebedev, G.V. Serga, I.V. Davydova, MATEC Web Conf., 226, ( (2018) 